\title{
VALORISATION OF SUGARCANE BAGASSE ASH IN THE MANUFACTURE OF LIME-STABILIZED BLOCKS
}

Jijo JAMES ${ }^{1 *}$, Pitchai Kasinatha PANDIAN ${ }^{1}$

\section{Abstract}

The study investigated the potential of lime in the manufacture of stabilized soil blocks and the valorisation of a solid waste, Bagasse Ash (BA), in its manufacture. A locally available soil was collected from a field and characterized in the soil laboratory as a clay of intermediate plasticity. This soil was stabilized using lime, the quantity of which was determined from the Eades and Grim pH test. The soil was stabilized using this lime content, amended with various $B A$ contents during mixing, and moulded into blocks of $19 \mathrm{~cm} \times 9 \mathrm{~cm} \times 9 \mathrm{~cm}$. The blocks were then moist cured for a period of 28 days, following which they were subjected to compressive strength, water absorption and efflorescence tests. The results of the tests revealed that the addition of $B A$ resulted in enhanced compressive strength of the blocks, increased the water absorption marginally, and resulted in no efflorescence in any of the combinations, although the limited combinations in the study could not produce enough strength to meet the specifications of the Bureau of Indian Standards. The study revealed that BA can be effectively valorised in the manufacture of stabilized soil blocks.

\section{Address}

1 Department of Civil Engineering, Tagore Engineering College, Rathinamangalam, Melakottaiyur P.O., Chennai - 127, India

* Corresponding author: jijothegreat@gmail.com

Key words

- Stabilized soil blocks,

- Lime,

- Bagasse ash,

- Compressive strength

- Water absorption,

- Efflorescence.

\section{INTRODUCTION}

Housing is an elementary requirement for all people, but the high cost of construction materials results in an economically weaker sect of the populace not being able to afford housing, especially in developing countries. This problem of a housing shortage also persists in India, where the rapid rise in the cost of land as well as the cost of materials is driving affordable housing out of the reach of the average person. The housing shortage in India currently stands at 60 million units, which is predicted to rise to 110 million units in 2022, which will require an investment of US\$ 250-260 billion (KPMG and NAREDCO 2014)Hence, in order to make housing affordable, innovations in construction materials to achieve cost reductions are essential, especially in developing countries like India. The valorisation of waste materials is one good option in achieving cost reductions as waste management is another area that is the focus of the research fraternity all over the world. Thus, the combination of waste management with cost reductions for the development of innovative low-cost construction materials provides the best of both worlds. Traditional earthen blocks have become popular in recent times, due to their economic competitiveness (Villamizar et al. 2012). Fired clay bricks consume huge amounts of energy in their manufacture, whereas compressed earth blocks like cement-stabilized blocks consume less than $10 \%$ of that energy 
(Walker 1995). Other advantages of these types of blocks include their low cost, construction performance, fire resistance and easy availability, while their drawbacks include low performance in the areas of durability, tensile strength, abrasion and impact toughness (Adam and Agib 2001). An earth or soil block is a construction or masonry unit of regular dimensions made from soil and called a compressed earth block when wet or damp soil is compressed at a high pressure to form the block or as a compressed stabilized earth block when any binder is used for the stabilization of the soil used in the manufacture of the block (James et al. 2016). A lot of materials have been adopted in the manufacture of soil blocks, but ordinary Portland cement has been one of the most common stabilizers used for soil stabilization (Basha et al. 2005; Hossain and Mol 2011). However, it is a well-known fact that cement manufacture results in carbon dioxide emissions.

Lime is another stabilizer adopted for stabilization of soils. Before the advent of cement, it was the most commonly adopted binder in construction. In fact, in Southern India, traditional constructions in the olden days adopted combinations of lime, jaggery and gall-nut powder in mortars to improve their performance and durability. The authors have conducted investigations of the said combination in soil stabilization as well (James and Pandian 2013; James et al. 2014). Despite its replacement as a primary binder by cement, lime can still function as a very good binder and can play a crucial role in the development of low-cost construction materials. Soil stabilization, including stabilized soil blocks, has become an avenue for the effective utilization of solid waste materials (James and Pandian 2015, 2016). Other researchers have also previously worked on the utilization of lime in the manufacture of stabilized blocks (Bharath et al. 2014; Nagaraj et al. 2014; Ciancio et al. 2014; Dass and Malhotra 1990; Guettala et al. 2006; Guettala et al. 2002; Maskell et al. 2014). There have been lots of efforts in the valorisation of waste materials in the manufacture of stabilized earth blocks. Coal ash and cassava peels (Villamizar et al. 2012), phosphogypsum (Ajam et al. 2009; Degirmenci 2008), rice husk ash and cement kiln dust (Hossain 2011), alumina filler waste (Miqueleiz et al. 2013) and egg shell waste (Adogla et al. 2016) are a few of the waste materials that have been adopted in the manufacture of blocks. There have also been attempts to valorise waste in combination with stabilizers like cement and/or lime in the manufacture of stabilized blocks like combinations of cement and slag/ quarry waste (Vijayaraghavan et al. 2009), cement and ceramic tile waste (Wattanasiriwech et al. 2009), lime and fly ash (Rushad et al. 2011), and cement and rice husk ash (Oyetola and Abdullahi 2006), to name a few. Similarly, in this investigation an attempt at the valorisation of sugarcane bagasse ash (BA), a waste from the sugar industry, in the manufacture of lime-stabilized blocks (LSB) has been made. The utilization of BA is not a new means to manufacture blocks. A lot of earlier researchers have attempted the valorisation of this waste in block manufacture both as a standalone stabilizer and in combinations with primary stabilizers (Greepala and Parichartpreecha 2011; James et al. 2016; Khobklang et al. 2008; Lima et al. 2012; Onchiri et al. 2014; Salim et al. 2014). However, there are also limited works wherein combinations of BA and lime have been adopted in the manufacture of stabilized blocks (Madurwar et al. 2014; Kulkarni et al. 2013; Alavéz-Ramírez et al. 2012). Thus, the primary objective of this work is to evaluate the performance of LSB with BA as a secondary additive.

\section{MATERIALS}

The various materials adopted in this investigation include virgin soil, used as the raw material for the block; lime, used as the stabiliz- er; and BA, adopted as the secondary additive; whose valorisation in the block manufacture has been attempted.

\subsection{Virgin Soil}

The virgin soil adopted in the manufacture of the blocks was collected from the Kanchipuram district of Tamil Nadu. The soil was tested for its geotechnical properties in the laboratory and classified, all in accordance with the relevant codes of the Bureau of Indian Standards (BIS). The properties of the soil adopted in the study are tabulated in Tab. 1.

Tab. 1: Properties of Soil

\begin{tabular}{ll}
\hline Property & Value \\
\hline Liquid Limit (BIS 1985) & $41.8 \%$ \\
\hline Plastic Limit (BIS 1985) & $14.5 \%$ \\
\hline Plasticity Index & $27.3 \%$ \\
\hline Shrinkage Limit (BIS 1972) & $10.1 \%$ \\
\hline Maximum Dry Density (BIS 1980) & $18.5 \mathrm{kN} / \mathrm{m}^{3}$ \\
\hline Optimum Moisture Content (BIS 1980) & $11.9 \%$ \\
\hline Unconfined Compressive Strength (BIS 1991) & $523.4 \mathrm{kPa}$ \\
\hline BIS Classification (BIS 1970) & $\mathrm{CI}$ \\
\hline
\end{tabular}

\subsection{Lime}

High quality, commercial grade, hydrated lime was adopted in this investigation. No special preparation methods were adopted for the lime, and it was used 'as is' from the package provided by the supplier. Hydrated lime is the most common form of lime adopted in soil stabilization activities.

\subsection{Bagasse Ash}

The major solid wastes generated from the sugar manufacturing process include sugarcane trash, bagasse, press mud, bagasse fly ash and spent wash (Balakrishnan and Batra 2011; Partha and Sivasubramanian 2006; Yadav and Solomon 2006). Bagasse is the fibrous residue that remains after the extraction of juice from cane. In many of the sugar processing industries, this bagasse is used as a fuel in boilers and results in the production of the by-product ash, called as 'BA'. BA has many uses and finds applications in the manufacture of low-cost adsorbents (Balakrishnan and Batra 2011), ceramics (Teixeira et al. 2008), biomass ash filters (Umamaheswaran et al. 2004), and concrete (Sales and Lima 2010; Sua-iam and Makul 2013), apart from applications in soil engineering. The BA adopted in this study was obtained from Thirutthani Sugar Mills Pvt. Ltd., Arakkonam district, Tamil Nadu, India. The chemical composition of the sugarcane BA adopted in the study is given in Tab. 2. Fig. 1 shows the X-ray diffraction (XRD) pattern of the BA. The mineralogical characterization of the BA shed light on the presence of cristobalite, quartz and calcium carbonate. Others have reported the presence of quartz, cristobalite, calcite, calcium phosphate, mullite, and iron oxide among others (Bahurudeen et al. 2015; Rodriguez-Diaz et al. 2015; Schettino and Holanda 2015; Torres Agredo 
Tab. 2 Chemical composition of Lime and BA

\begin{tabular}{c|c|c|c|c|c|c|c|c|c|c}
\hline$(\%)$ of & $\mathrm{SiO}_{2}$ & $\mathrm{Al}_{2} \mathrm{O}_{3}$ & $\mathrm{CaO}$ & $\mathrm{Fe}_{2} \mathrm{O}_{3}$ & $\mathrm{~K}_{2} \mathrm{O}$ & $\mathrm{MgO}$ & $\mathrm{Na}_{2} \mathrm{O}$ & $\mathrm{P}_{2} \mathrm{O}_{5}$ & $\mathrm{TiO}_{2}$ & $\mathrm{SO}_{3}$ \\
\hline Lime & 0.245 & 0.053 & 72.267 & 0.037 & 0.003 & 14.604 & 0.047 & 0.005 & 0.003 & 0.048 \\
\hline BA & 35.17 & 0.281 & 2.07 & 5.22 & 3.75 & 0.91 & 0.01 & 1.03 & 0.02 & 0.03 \\
\hline
\end{tabular}

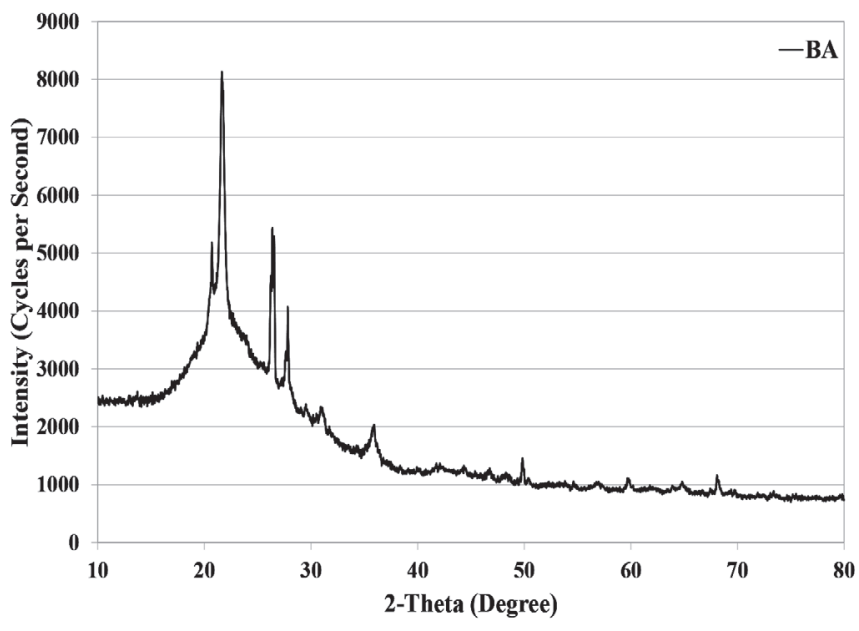

Fig. 1: X-Ray Diffractogram of Sugarcane BA

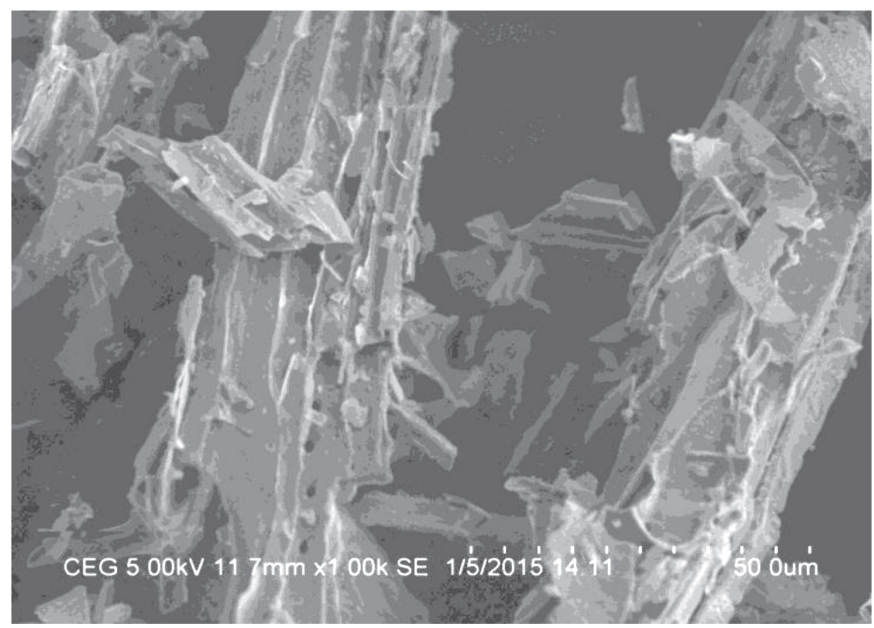

Fig. 2: SEM Micrograph of BA

et al. 2014). Fig. 2 shows the microstructure of BA. It clearly reveals well-burnt flakes of bagasse.

\section{METHODOLOGY}

The experimental methodology began with the preparation of the soil sample in accordance with the BIS code IS 2720 Part 1 (BIS 1983); it was tested for its geotechnical properties and classified as intermediate plastic clay (CI). Lime was used 'as is' out of the packaging supplied. The BA was sieved through a 300 micron BIS sieve to improve its reactivity with soil and lime. The BA was subjected to X-ray fluorescence (XRF) to determine its chemical composition, $\mathrm{XRD}$ for determination of its mineralogy, and scanning electron microscopy (SEM) for its morphological characterization. Madurwar et al. (2014) had also characterized BA similarly to determine its

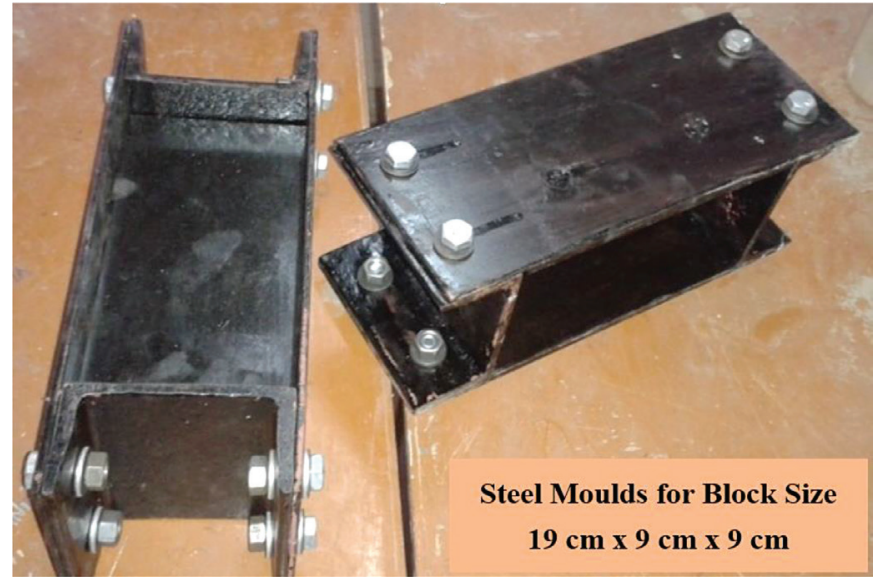

Fig. 3: Steel moulds adopted for the moulding of stabilized blocks

properties. A block size of $19 \mathrm{~cm} \times 9 \mathrm{~cm} \times 9 \mathrm{~cm}$ was selected out of the three different sizes suggested in the BIS code IS 1725 (BIS 1982) for stabilized blocks. Two steel moulds were fabricated for the manufacture of stabilized blocks with the selected dimensions. Fig. 3 shows the fabricated moulds adopted for the study.

The minimum lime content required to raise the $\mathrm{pH}$ of soil to 12.4 is the amount of lime required for the modification of soil properties (ASTM 1999) and is called the "initial consumption of lime". This lime content was determined from the Eades and Grim $\mathrm{pH}$ test (Eades and Grim 1966) and was used to stabilize the soil under investigation. The BA contents used to amend the stabilization process were selected at random. The soil blocks were cast to a fixed density of $18.5 \mathrm{kN} / \mathrm{m}^{3}$ and a moisture content of $12 \%$. After the blocks were cast, they were sprinkle cured for a period of 28 days and covered with plastic gunny bags. A detailed description of the casting of the blocks is described in an earlier work (James et al. 2016). Fig. 4 graphically describes the casting of the LSB. The stabilized blocks were then subjected to compressive strength, water absorption and efflorescence tests as per the BIS recommendations (BIS 1982) in accordance with the BIS code IS 3495 (BIS 1992). The average of three block test results was taken for each property for a particular combination. 


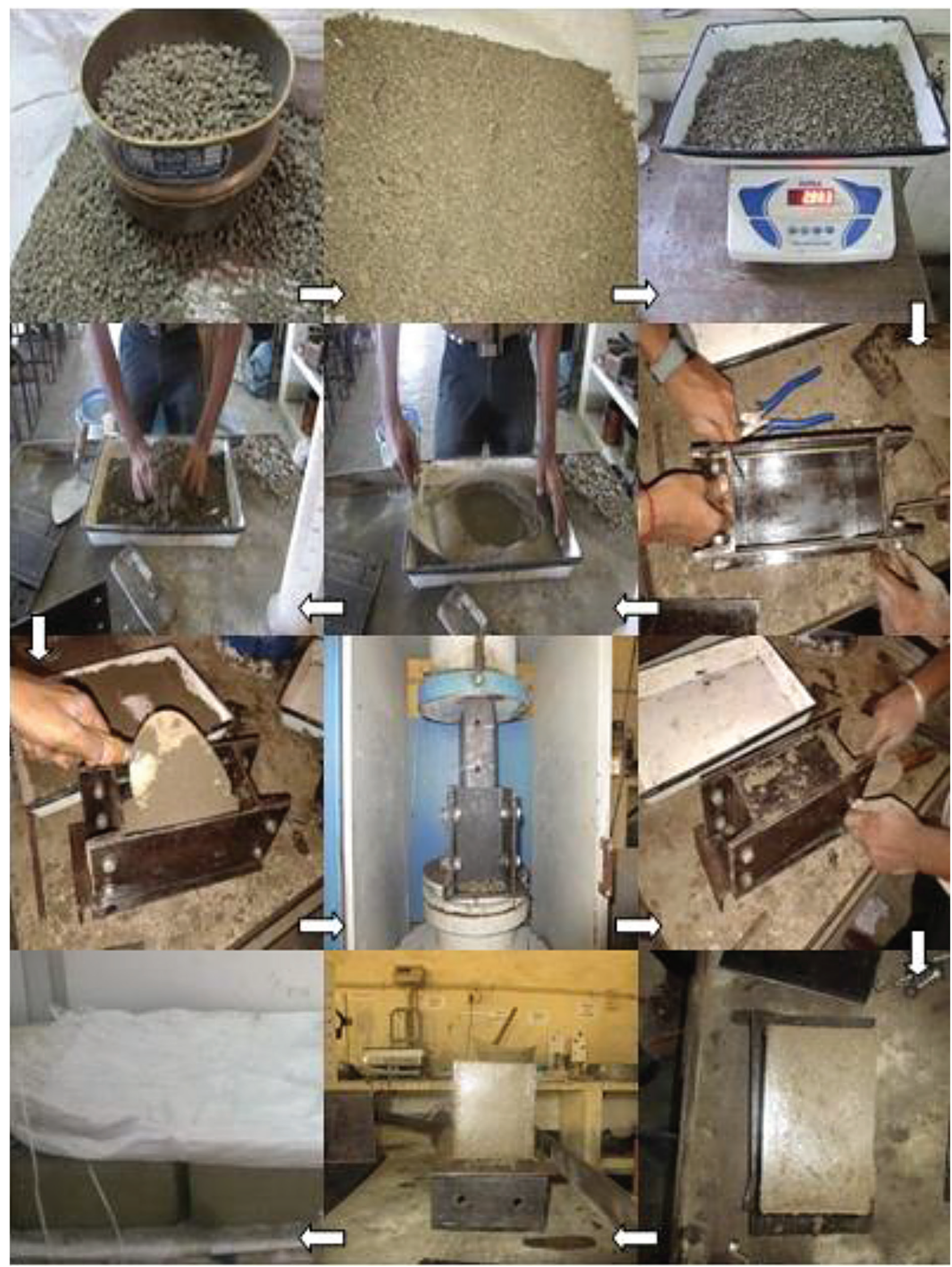

Fig. 4: Graphic description of the casting and curing of stabilized earth blocks 


\section{RESULTS AND DISCUSSION}

The initial consumption of lime that was determined by the Eades and Grim pH test turned out to be 6\%, as seen in Fig. 5. The soil under investigation was stabilized with $6 \%$ lime and amended with three different BA contents of $4 \%, 6 \%$ and $8 \%$. In earlier studies, wherein combinations of lime and BA were adopted for the manufacture of stabilized blocks, Alavéz-Ramírez et al. (2012) adopted 10\% lime, while Madurwar et al. (2014) and Kulkarni et al. (2013) adopted 20\% lime for stabilization of the soil for making the blocks. The results of the performance of the BA-amended LSB are discussed in the following sections.

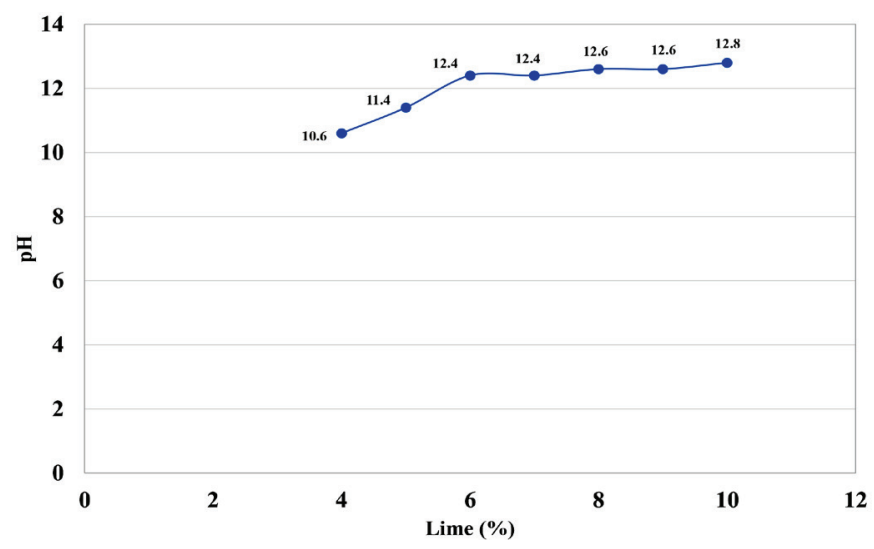

Fig. 5: Determination of the initial consumption of the lime

\subsection{Compressive Strength of LSB}

Fig. 6 shows the compressive strength of $6 \%$ LSB amended with BA. It can be seen that the addition of BA to the lime stabilization of the blocks resulted in an increase in the compressive strength of the block. The strength of the LSB increased from 1.687 MPa to 1.87 MPa, a gain of $0.183 \mathrm{MPa}$. The BIS specification in IS 1725 (BIS 1982) stipulates two classes of stabilized blocks, i.e., class 20 with a minimum permissible strength of $1.96 \mathrm{MPa}$ and Class 30 with a minimum permissible strength of $2.94 \mathrm{MPa}$. It can be seen that in the present case, the strength of LSB stabilized with $6 \%$ lime is not enough to achieve the minimum specifications of a class 20 block. However, the addition of BA to the stabilization process increases the strength to $1.87 \mathrm{MPa}$; although that is still not enough to meet the strength requirement of a class 20 block, it is off the minimum requirement by less than $5 \%$ versus the $16 \%$ shortage of a pure LSB. Earlier studies have reported higher strengths compared to the ones achieved in

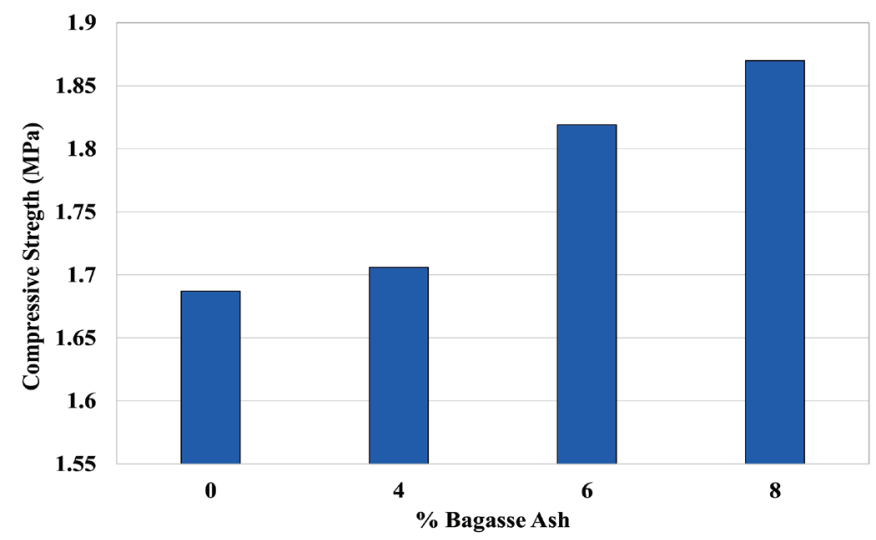

Fig. 6: Compressive strength of 6\% lime stabilized soil amended with $B A$ the present work. However, it should be noted that the compressive strength of the stabilized block depends upon the soil type, the type and amount of stabilizer, and the compaction pressure used to form the block (Adam and Agib 2001). One particular reason for the low strength may be due to the low amount of lime (6\%) adopted for the stabilization process when compared to earlier studies (10-20\%) (Alavéz-Ramírez et al. 2012; Kulkarni et al. 2013; Madurwar et al. 2014). Thus, it can be seen that the addition of BA is capable of raising the strength of the LSB to meet standards, which in the present case is limited due to the combination of the BA considered for the investigation. Higher combinations of BA can further reveal the full potential of the combination for achieving low-cost construction material.

Fig. 7 shows the percentage strength gain with the percentage of BA. It can be seen that at a BA content of $4 \%$, the percentage strength gain was a meagre $1.12 \%$. Thus, it can be concluded that for the soil under investigation, a BA content of $4 \%$ and below cannot produce much of an effect on the strength of a stabilized block. With an increase in the BA content, the percentage strength gain also increased to $7.82 \%$ for a $6 \%$ BA addition, whereas the percentage strength gain increased to $10.85 \%$ for an $8 \%$ addition of BA. It can be noted, however, that the gain in strength was significant between $4 \%$ and $6 \%$ BA, but a similar gain was not seen between the $6 \%$ and $8 \%$ BA additions. Thus, it can be concluded that by increasing the BA content, the extent of the strength gain initially increases but slows down with higher BA contents.

When taking a look at earlier research, it was found that a lot of research has been done with combinations of cement and BA in the manufacture of stabilized blocks (Greepala and Parichartpreecha 2011; James et al. 2016; Khobklang et al. 2008; Lima et al. 2012). However, the combination of lime and BA in the manufacture of blocks has been limited, probably due to the low levels of strength achieved by lime when compared to cement in the stabilization of blocks. Nevertheless, a few researchers have gone ahead with the combination and found contrasting results. However, the combinations and test conditions adopted by different investigators were different. In order to reduce the results to a comparable level, the authors reduced the contents of the lime and BA as a ratio of the additive to the stabilizer. However, as the block density data for all the previous investigations was not available, the compressive strength could not be normalized for the pressure applied as done in an earlier work (James et al. 2016). Fig. 8 shows a comparison of the present work with the earlier works of Madurwar et al. (2014) and Alavéz-Ramírez et al. (2012) in terms of the 28 days compressive strength of the blocks. The work done by Kulkarni et al. (2013) was similar but could not be analysed since compressive strength was reported for only 21 days of curing in their study.

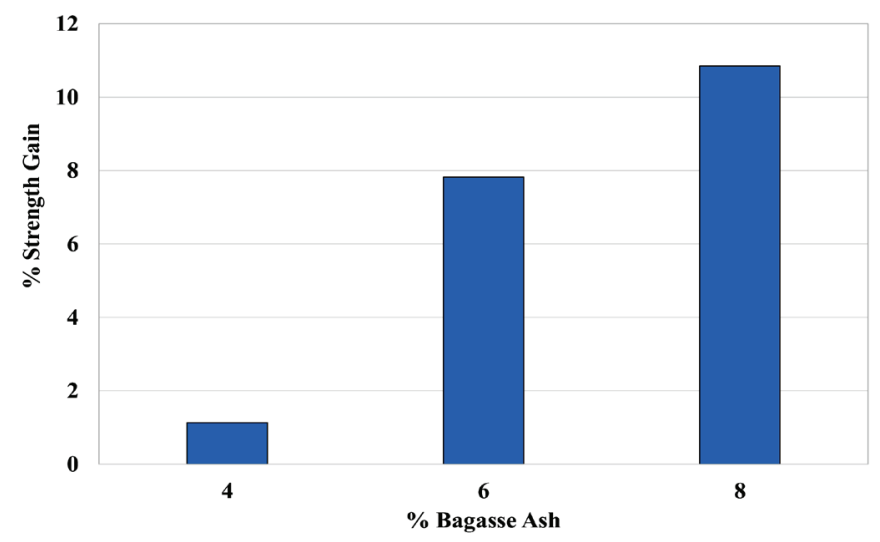

Fig. 7: Percentage strength gain of $L S B$ with $B A$ 
At the outset, it is clear that the strength results of the present study is the lowest in comparison with both the previous studies. This may be attributed to the low lime content adopted in the present work when compared to the earlier investigations. It is also reported in the literature that the properties of soil stabilized at the initial consumption of lime, are only capable of being modified without much gain in strength; however, a lime content higher than the initial consumption results in the development of strength (Bell 1996; Thompson 1967). Alavéz-Ramírez et al. (2012) reported very high compressive strengths with combinations of BA and lime, while Madurwar et al. (2014) reported strength in between the two studies. Alavéz-Ramírez et al. (2012) adopted only one BA content with lime for stabilizing the soil blocks and therefore had only two combinations in total, including the control specimen. The probable reasons for the high compressive strength may be a higher lime content along with a very high compaction load of 24 tons applied for the manufacture of the blocks. As mentioned earlier, applied pressure is one of the important factors that influences the strength of stabilized blocks. Madurwar et al. (2014) reported a reduction in the strength of stabilized blocks with an increase in BA content. However, their work did not report the strength achieved by pure LSB, because of which it could not be concluded as to whether the addition of BA resulted in a positive strength gain or not. Out of the three studies compared, a positive strength gain with an increase in the SBA/lime ratio could be found in the present study and in the work done by Alavéz-Ramírez et al. (2012). The other work reports a reduction in strength of the stabilized block with an increase in the SBA/lime ratio, but it should be noted that their block was made up of quarry dust rather than soil, which may have been an influencing factor. The three investigations clearly show the effects of the stabilizer and additive content, soil type and pressure applied on the strength of the stabilized blocks.

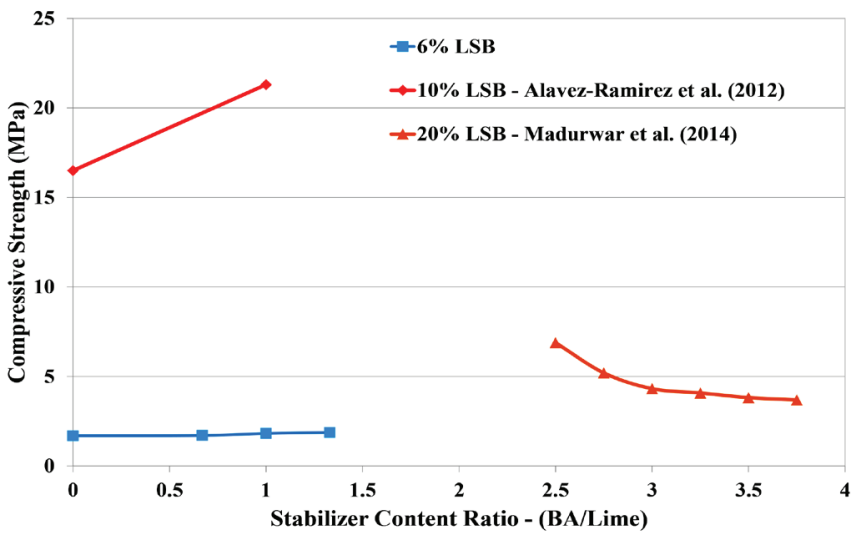

Fig. 8: Comparison of the compressive strength of the present study with earlier works (Alavéz-Ramirez et al. 2012; Madurwar et al. 2014)

\subsection{Water Absorption of LSB}

The effect of water immersion on the absorption of LSB amended with BA is shown in Fig. 9. BIS recommends a maximum permissible water absorption of $15 \%$ for stabilized soil blocks. The addition of BA to LSB results in an increase in the water absorption of the blocks. The water absorption increases from the control value of $7.46 \%$ to $8.38 \%$ with an $8 \%$ addition of BA, which is an increase of less than $1 \%$. The water absorption of the other combinations i.e., $4 \%$ and $6 \%$ BA additions are $7.83 \%$ and $7.97 \%$ respectively. It can be seen that the water absorption of all the combinations of lime-BA blocks are well below the permissible limit prescribed by BIS. In fact, all the water absorption values are around the halfway mark of the prescribed limit. An increase in water absorption due to the addition of BA was also reported by earlier investigators (Greepala and Parichartpreecha 2011; James et al. 2016). Thus, it can be concluded that the addition of BA, although results in a marginal increase in the water absorption, it is not detrimental to the performance of the blocks.

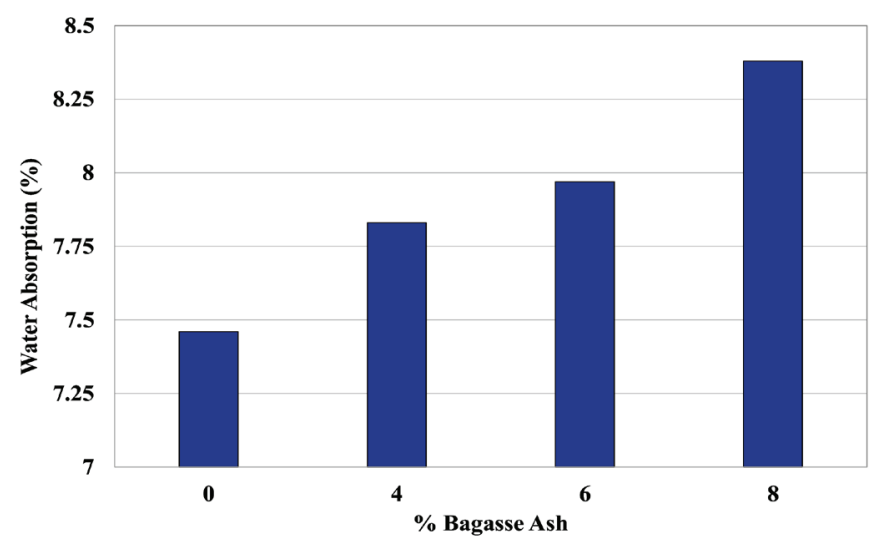

Fig. 9: Water absorption of LSB amended with BA

\subsection{Efflorescence of LSB}

Efflorescence is the deposition of salt on the exterior of a block surface when immersed in water. An efflorescence test was carried out on the LSB in accordance with the BIS code IS 3495 (BIS 1992). The results of the efflorescence tests on the stabilized blocks are tabulated in Tab. 3, which clearly reveals that no efflorescence was noticed on any of the lime-BA combinations.

Tab. 3: Efflorescence of Stabilized Blocks

\begin{tabular}{c|c|c}
\hline Lime Content (\%) & SBA Content (\%) & Efflorescence \\
\hline 6 & 0 & Nil \\
\hline 6 & 4 & Nil \\
\hline 6 & 6 & Nil \\
\hline 6 & 8 & Nil \\
\hline
\end{tabular}

\subsection{Relationship between Compressive Strength and $\%$ BA Content}

The results of the compressive strength tests reveal that the BA contents investigated in this work were not enough to achieve the minimum compressive strength of class 20 blocks; however, the values were close to the minimum values. Hence, based on the available data, a fit was attempted to explain the relationship between compressive strength and percentage BA content. Okafor and Ewa (2012) tried developing models for predicting the compressive strength of Obudu earth blocks stabilized with cement kiln dust. In the present study, however, due to very limited data, a guideline rather than a full-scale model has been attempted for determining the minimum BA content for achieving the minimum standard strength. Similarly, Al-zaidyeen and Al-qadi (2015) also attempted to derive a relationship to determine the optimal phosphogypsum dosage for the stabili- 
zation of pavement layers in their study. Fig. 10 shows the relationship between compressive strength and \% BA content for 6\% LSB. It can be seen that the fit between compressive strength and \% BA content has a good $\mathrm{R}^{2}$ value of 0.94 . The fit was also extended in an attempt to forecast the minimum BA content required to achieve the standard strength of a class 20 block. Based on the relationship equation obtained from the fit, it was found that a minimum BA content of $9.425 \%$ was required for achieving a strength of $1.96 \mathrm{MPa}$ for class 20 blocks. Thus, it can be concluded that 6\% LSB amended with $10 \%$ BA to achieve a strength higher than class 20 blocks can be recommended. However, the accuracy of the prediction needs to be verified by conducting actual testing with higher combinations of BA in future investigations.

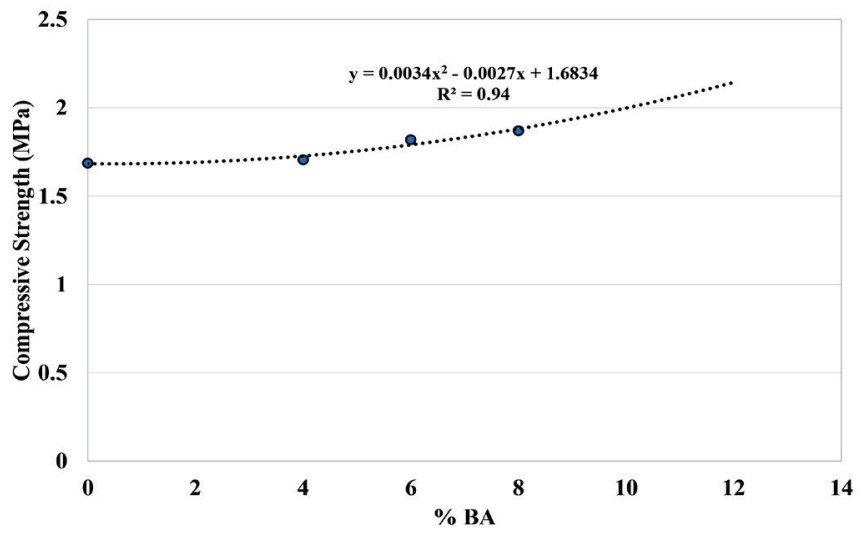

Fig. 10: Relationship between strength and \% BA for $6 \%$ LSB

\section{CONCLUSIONS}

The study investigated potential combinations of lime and BA in stabilizing a locally available soil for the manufacture of stabilized blocks. Based on the results of the experimental investigations carried out in the laboratory, the following points may be concluded:

(i) The lime stabilization of a locally available soil stabilized at the initial consumption of lime was not enough to meet the strength requirements of class 20 block specifications of BIS.

(ii) The addition of BA to the lime stabilization of soil blocks resulted in an increase in the strength of the block. $8 \% \mathrm{BA}$ produced the maximum compressive strength of the block; however, it was still not enough to meet the strength requirements of class 20 blocks.

(iii) The addition of BA resulted in an increase in the water absorption of the stabilized block, but the water absorption levels were well within the maximum permissible water absorption limits of BIS.

(iv) The BA amended LSB did not show any signs of efflorescence for any of the combinations tested in this investigation.

(v) The BA combinations evaluated in this investigation were not sufficient to achieve the requisite strength; hence, the results of the tests were used to derive a relationship between compressive strength and the percentage of the BA amendment, which was used to forecast that a minimum of $9.425 \%$ BA was required for achieving the strength of a class 20 block. Thus, it can be seen that BA can be effectively valorised in the manufacture of stabilized blocks.

(vi) When compared to earlier investigations, the strength achieved by lime stabilization at the initial consumption of lime in the present study was low; it is therefore recommended that future investigations with a higher optimum lime content with BA can be carried out to investigate their strength performance.

(vii) The durability and wear resistance of stabilized soil blocks stabilized at an optimum lime content amended with BA can also be taken up in future investigations.

It is concluded that BA as a by-product from the sugar industries is a potential alternative material for use in construction materials in countries where it is generated in huge proportions, thereby achieving effective waste management while producing low cost and innovative construction materials.

\section{Acknowledgements}

The authors are grateful to the management of Tagore Engineering College and Bharath University, Chennai, India, for providing the laboratory facilities for carrying out this investigation. We would also like to acknowledge the XRF facility provided by SAIF, IIT-Bombay, Mumbai, India and the XRD and SEM facilities provided by CNST, Anna University, Chennai. The authors also extend their thanks to Mr. M. Sasi Kumar, Laboratory Instructor, Soil Engineering Laboratory, and the students of B.E., Civil Engineering, Tagore Engineering College, for their help during the investigation. 


\section{REFERENCES}

Adam, E. A., - Agib, A. R. A., (2001) Compressed Stabilized Earth Block Manufacture in Sudan, Paris, France, pp. 1-114. Available at: http://unesdoc.unesco.org/images/0012/001282/128236e.pdf

Adogla, F., - Paa, P., - Yalley, K., - Arkoh, M., (2016) Improving Compressed Laterite Bricks using Powdered Eggshells. The International Journal of Engineering and Science, Vol. 5, No. 4, pp. 65-70.

Ajam, L., - Ben, M., -Sfar, H., - El, R., (2009) Characterization of the Tunisian phosphogypsum and its valorization in clay bricks. Construction and Building Materials, Vol. 23, No. 10, pp. 3240-3247.

Alavéz-Ramírez, R., - Montes-García, P., - Martínez-Reyes, J., Altamirano-Juárez, D. C., - Gochi-Ponce, Y., (2012) The use of sugarcane bagasse ash and lime to improve the durability and mechanical properties of compacted soil blocks. Construction and Building Materials, Vol. 34, pp. 296-305.

Al-zaidyeen, S. M., and Al-qadi, A. N. S., (2015) Effect of Phosphogypsum As a Waste Material in Soil Stabilization of Pavement Layers. Jordan Journal of Civil Engineering, Vol. 9, No. 1, pp. 1-7.

ASTM (1999) D6276 Standard Test Method for Using $p H$ to Estimate the Soil-Lime Proportion Requirement. United States, pp. 1-4.

Bahurudeen, A., - Wani, K., - Basit, M.A., - Santhanam, M., (2015) Assesment of Pozzolanic Performance of Sugarcane Bagasse Ash. Journal of Materials in Civil Engineering, Vol. 28, p. 04015095 .

Balakrishnan, M., - Batra, V.S., (2011) Valorization of solid waste in sugar factories with possible applications in India : a review. Journal of Environmental Management, Vol. 92, No. 11, pp. 2886-91.

Basha, E. A., - Hashim, R., - Mahmud, H. B., - Muntohar, A. S., (2005) Stabilization of residual soil with rice husk ash and cement. Construction and Building Materials, Vol. 19, No. 6, pp. 448-453.

Bell, F. G., (1996) Lime stabilization of clay minerals and soils. Engineering Geology, Vol. 42, No. 4, pp. 223-237.

Bharath, B., - Reddy, M., - Pathan, J., - Patel, R., (2014) Studies on Stabilised Adobe Blocks. International Journal of Research in Engineering and Technology, Vol. 3, No. 6, pp. 259-264.

BIS (1970) IS 1498 Classification and Identification of Soils for General Engineering Purposes. India, pp. 4-24.

BIS (1972) IS 2720 Methods of Test for Soils: Part 6 Determination of Shrinkage Factors. India, pp. 1-12.

BIS (1980) IS 2720 Methods of Test for Soils: Part 7 Determination of Water Content-Dry Density Relation Using Light Compaction. India, pp. 1-9.

BIS (1982) IS 1725: Specification for Soil Based Blocks Used in General Building Construction. India, pp. 1-7.

BIS (1983) IS 2720 Methods of Test For Soils: Part 1 - Preparation of Dry Soil Sample for Various Tests. India, pp. 1-10.

BIS (1985) IS 2720 Methods of Test for Soils: Part 5 Determination of Liquid and Plastic Limit, India. pp. 1-16.
BIS (1991) IS 2720 Methods of Test for Soils: Part 10 - Determination of Unconfined Compressive Strength. India, pp. 1-4.

BIS (1992) IS 3495 Parts 1-4 : Methods of Tests of Burnt Clay Building Brick. India, pp. 1-7.

Ciancio, D., - Beckett, C. T. S., - Carraro, J. A. H., (2014) Optimum lime content identification for lime-stabilised rammed earth. Construction and Building Materials, Vol. 53, pp. 59-65.

Dass, A., - Malhotra, S. K., (1990) Lime-stabilized red mud bricks. Materials and Structures, Vol. 23, pp. 252-255.

Degirmenci, N., (2008) The using of waste phosphogypsum and natural gypsum in adobe stabilization. Construction and Building Materials, Vol. 22, No. 6, pp. 1220-1224.

Eades, J. L., - Grim, R. E., (1966) A Quick Test to Determine Lime Requirements for Lime Stabilization. Highway Research Record, Vol. 139, pp. 61-72.

Greepala, V., - Parichartpreecha, R., (2011) Effects of Using Fly Ash, Rice Husk Ash and Bagasse Ash as Replacement Materials on the Compressive Strength and Water Absorption of Lateritic Soil-Cement Interlocking Blocks. Proceedings of 9th Australasian Masonry Conference, 15 - 18 February, Queenstown, New Zealand, pp. 583-603.

Guettala, A., - Abibsi, A., - Houari, H., (2006) Durability study of stabilized earth concrete under both laboratory and climatic conditions exposure. Construction and Building Materials, Vol. 20, No. 3, pp. 119-127.

Guettala, A., - Houari, H., - Mezghiche, B., - Chebili, R., (2002) Durability of Lime Stabilized Earth Blocks. Courrier du Savoir, Vol. 2, No. 1, pp. 61-66.

Hossain, K. M. A., (2011) Stabilized Soils Incorporating Combinations of Rice Husk Ash and Cement Kiln Dust. Journal of Materials in Civil Engineering, Vol. 23, No. 9, pp. 1320-1327.

Hossain, K. M. A., - Mol, L., (2011) Some engineering properties of stabilized clayey soils incorporating natural pozzolans and industrial wastes. Construction and Building Materials, Vol. 25, No. 8, pp. 3495-3501.

James, J., - Lakshmi, S. V., - Pandian, P. K., - Vanitha, S., (2014) Engineering Performance of Lime Stabilized Soil Admixed with Natural Materials. International Journal of Applied Environmental Sciences, Vol. 9, No. 4, pp. 973-6077.

James, J., - Pandian, P. K., (2013) Performance Study on Soil Stabilisation Using Natural Materials. International Journal of Earth Sciences and Engineering, Vol. 6, No. 1, pp. 194-203.

James, J., - Pandian, P. K., (2015) Soil Stabilization as an Avenue for Reuse of Solid Wastes : A Review. Acta Technica Napocensis: Civil Engineering and Architechture, Vol. 58, No. 1, pp. 50-76.

James, J., - Pandian, P. K., (2016) Industrial Wastes as Auxiliary Additives to Cement / Lime Stabilization of Soils. Advances in Civil Engineering, Vol. 2016, No. Article ID 1267391, pp. 1-17.

James, J., - Pandian, P. K., - Deepika, K., - Venkatesh, J. M., Manikandan, V., - Manikumaran, P., (2016) Cement Stabilized Soil Blocks Admixed with Sugarcane Bagasse Ash. Journal of Engineering, Vol. 2016, No. Article ID 7940239, pp. 1-9. 
Khobklang, P., - Nokkaew, K., - Greepala, V., (2008) Effect of Bagasse Ash on Water Absorption and Compressive Strength of Lateritic Soil Interlocking Block. In: Limbachiya, M. C., and Kew, H. Y., (eds): Proceedings of the International Conference on Excellence in Concrete Construction Through Innovation, 9-10 September, Kingston upon Thames, United Kingdom, pp. 181-185.

KPMG - NAREDCO (2014) Decoding housing for all by 2022. pp. 1-31, Available at: https://www.kpmg.com/IN/en/IssuesAndInsights/ArticlesPublications/Documents/Decoding-Housing-for-all-2022.pdf

Kulkarni, A., - Raje, S., - Rajgor, M., (2013) Bagasse Ash as an Effective Replacement in Fly Ash Bricks. International Journal of Engineering Trends and Technology, Vol. 4, No. 10, pp. 4484-4489.

Lima, S. A., - Varum, H., - Sales, A., - Neto, V. F., (2012) Analysis of the mechanical properties of compressed earth block masonry using the sugarcane bagasse ash. Construction and Building Materials, Vol. 35, pp. 829-837.

Madurwar, M. V., - Mandavgane, S. A., - Ralegaonkar, R. V., (2014) Use of Sugarcane Bagasse Ash as Brick Material. Current Science, Vol. 107, No. 6, pp. 1044-1051.

Maskell, D., - Heath, A., - Walker, P., (2014) Inorganic stabilisation methods for extruded earth masonry units. Construction and Building Materials, Vol. 71, pp. 602-609.

Miqueleiz, L., - Ramirez, F., - Oti, J.E., - Seco, A., - Kinuthia, J.M., - Oreja, I., - Urmeneta, P., (2013) Alumina filler waste as clay replacement material for un fi red brick production. Engineering Geology, Vol. 163, pp. 68-74.

Nagaraj, H. B., - Sravan, M. V., - Arun, T. G., - Jagadish, K. S., (2014) Role of lime with cement in long-term strength of Compressed Stabilized Earth Blocks. International Journal of Sustainable Built Environment, Vol. 3, No. 1, pp. 54-61.

Okafor, F. O., - Ewa, D. E., (2012) Predicting The Compressive Strength of Obudu Earth Blocks Stabilized with Cement Kiln Dust. Nigerian Journal of Technology, Vol. 31, No. 2, pp. 149-155.

Onchiri, R., - James, K., - Sabuni, B., - Busieney, C., (2014) Use Of Sugarcane Bagasse Ash As A Partial Replacement For Cement In Stabilization Of Self-Interlocking Earth Blocks. International Journal of Civil Engineering and Technology, Vol. 5, No. 10, pp. 124-130.

Oyetola, E. B., - Abdullahi, M., (2006) The Use of Rice Husk Ash in Low - Cost Sandcrete Block Production. Leonardo Electronic Journal of Practices and Technologies, Vol. 5, No. 8, pp. 58-70.

Partha, N., - Sivasubramanian, V., (2006) Recovery of Chemicals from Pressmud - A Sugar Industry Waste. Indian Chemical Engineer, Vol. 48, No. 3, pp. 160-163.

Rodriguez-Diaz, J. M., - Garcia, J. O. P., - Sanchez, L. R. B., - da Silva, M. G. C., - da Silva, V. L., - Arteaga-Perez, L. E., (2015) Comprehensive Characterization of Sugarcane Bagasse Ash for Its Use as an Adsorbent. Bioenergy Research, Vol. 8, No. 4, pp. 1885-1895.

Rushad, S. T., - Kumar, A., - Duggal, S. K., - Mehta, P. K., (2011) Experimental Studies on Lime-Soil-Fly Ash Bricks. International Journal of Civil and Structural Engineering, Vol. 1, No. 4, pp. 994-1002.

Sales, A., - Lima, S. A., (2010) Use of Brazilian sugarcane bagasse ash in concrete as sand replacement. Waste Management, Vol. 30, No. 6, pp. 1114-1122.
Salim, R. W., - Ndambuki, J. M., - Adedokun, D. A., (2014) Improving the Bearing Strength of Sandy Loam Soil Compressed Earth Block Bricks Using Sugarcane Bagasse Ash. Sustainability, Vol. 6, No. 6, pp. 3686-3696.

Schettino, M. A. S., - Holanda, J. N. F., (2015) Characterization of Sugarcane Bagasse Ash Waste for Its Use in Ceramic Floor Tile. Procedia Materials Science, Vol. 8, pp. 190-196.

Sua-iam, G., - Makul, N., (2013) Use of increasing amounts of bagasse ash waste to produce self-compacting concrete by adding limestone powder waste. Journal of Cleaner Production, Vol. 57, pp. 308-319.

Teixeira, S. R., - de Souza, A. E., - de Almeida Santos, G. T., Vilche Peña, A. F., - Miguel, Á. G., (2008) Sugarcane Bagasse Ash as a Potential Quartz Replacement in Red Ceramic. Journal of the American Ceramic Society, Vol. 91, No. 6, pp. 1883-1887.

Thompson, M. R., (1967) Factors influencing the plasticity and strength of lime soil mixtures. University of Illunois Bulletin, Vol. 64, No. 100, pp. 1-20.

Torres Agredo, J., - de Gutiérrez, R. M., - Escandón Giraldo, C. E., - González Salcedo, L. O., (2014) Characterization of sugar cane bagasse ash as supplementary material for Portland cement. Ingenieria e Investigacion, Vol. 34, No. 1, pp. 5-10.

Umamaheswaran, K., - Batra, V. S., - Bhagavanulu, D. V. S., (2004) Development of Biomass Ash Filters for High Temperature Applications. Proceedings of International Symposium of Research Students on Materials Science and Engineering, December 20-22, IIT-Madras, Chennai, India, pp. 1-8.

Vijayaraghavan, C., - James, J., - Marithangam, S., (2009) Cost Effective Bricks in Construction : A Performance Study International Journal of Applied Engineering Research, Vol. 4, No. 3, pp. 227-234.

Villamizar, M. C. N., - Araque, V. S., - Reyes, C. A. R., - Silva, R. S., (2012) Effect of the addition of coal-ash and cassava peels on the engineering properties of compressed earth blocks. Construction and Building Materials, Vol. 36, pp. 276-286.

Walker, P. J., (1995) Strength, Durability and Shrinkage Characteristics of Cement Stabilised Soil Blocks. Cement and Concrete Composites, Vol. 17, No. 4, pp. 301-310.

Wattanasiriwech, D., - Saiton, A., - Wattanasiriwech, S., (2009) Paving blocks from ceramic tile production waste. Journal of Cleaner Production, Vol. 17, pp. 1663-1668.

Yadav, R. L., - Solomon, S., (2006) Potential of developing sugarcane by-product based industries in India. Sugar Tech, Vol. 8, No. 2, pp. 104-111. 